\title{
QUALITY ASSESSMENT ABOUT STANDARDS FOR WELLNESS SERVICES AND CERTIFIED SKILLS OF SPECIALIZED STAFF
}

\author{
B. Dimitrova* \\ Faculty of Public Health, Healthcare and Tourism, National Sports Academy "Vassil Levski", \\ Sofia, Bulgaria
}

\begin{abstract}
PURPOSE: The aim of this study was to establish the quality assessment about standards for Wellness services and certified skills of specialized staff in the Bulgarian niche tourism by setting out a range scale by significance on the base of scientific indicators.

METHODS: During the period of March-June 2017 a Psychometric measurement of experts' point of view was conducted among Bulgarian professionals from various Wellness \& SPA \& Thalasso centres: employers, executives, investors, entrepreneurs, managers, executives and students from specific programs in the field. The experts' opinions were measured by an adapted version of the Survey Questionnaire for online use with Google Drive tools.

RESULTS: The psychometric measurement results on the meanings of numbers (through the order for Afixed question by-X of B-number of questions) placed on all questions asked. We obtain a range scale for ranking the relative significance of the studied properties for the quality services and centres in the Bulgarian Niche tourism.

CONCLUSIONS: The results in our study are in support of the needed action plan in co-partnership between the Bulgarian Institutions, professional and non-governmental organisation for developing and adopting new state standards; setting requirements for categorization of Wellness \& SPAs and quality assessment not only for the facilities, but for the applied procedures and services; and also providing certification for the specialized staff according to the European qualification framework for all levels starting from secondary and finishing at "Doctoral degree $(\mathrm{PhD})$ ".
\end{abstract}

Keywords: Wellness culture, Niche tourism, Staff education, Wellness services, range scale

\section{INTRODUCTION}

Six of the top 10 world Wellness (for applying healthy life style) tourism destinations are in Europe (1). Growth forecasts suggest opening up the potential of Eastern Europe (2). The European Wellness industry is aware that in order to maintain its leading positions and service quality, ensuring relevant training is a critical success factor (3), both for current and future employees involved in the provision of services ensuring the satisfactory delivery of the tasks assigned $(4,5)$. During the first decade of the 21 st century the Wellness tourism become a significant part of the

\footnotetext{
*Correspondence to: Bistra Dimitrova, D.Sc, National Sports Academy "Vassil Levski” Sofia, Faculty of public health, healthcare and tourism, Department Aquatic sports, E-mail: dimitrova.bistra@yahoo.com
}

revenues in the Global Niche tourism inside of it the Recreation programs (6). In a large number of publications shares information that have a crucial need for well trained staff to combating the existing lack of specialized staff. Worldwide the Niche tourism is developed under the costumer's need, so is spontaneous (7), without sustainable vision or SWOT analysis (8). The Wellness industry is the only sector in the Global Tourism, which showed average growth of $7-8 \%$ per year during the economic crisis (9). According to the recent research made by Pesheva, A. et al. (2018): "Low individual health literacy, means that Bulgarians may not be able to effectively exercise their choice when making healthcare decisions" (10) or respectively Wellness destination travel. The drafting of a new educational instrument for certification requires the job to be placed in the socio- 
economic context in which it is a part. Prospects of the Wellness tourism industry also impact on the job position of a "Wellness Instructor". It is important that the new educational / training / certified program not only be made on existing context but based on elements that are expected in the future and have the strongest influence on this job position. Hence, to characterise the social and economic context in which the contractors will work in support of the Wellness culture in Bulgaria research on existing reports for the need of professionalisation of the position of "Wellness Instructor" were conducted by the Balkan cluster for Health, Wellness and SPA (Sanus per Aqua) tourism, under our supervision as a scientific director. We are the editor in chief of all the content of the intellectual products for the new job position "Wellness Instructor". This study presents the Bulgarian impact inside of a collective work of international consortium, all partners in Erasmus+ project (WELVET - Austria, Estonia, United Kingdom and Macedonia, 2016-2018). Expert's opinions in the Global Wellness Institute reports (GWI, 2013-2018). Revisiting our last 5 years publications and educational models for the Wellness culture, we predicted before their time and during the WELVET Conference, 2018, June 9-11th, we launch the our concept as a new Wellness Balkan Brand the "Wellness for all". As we work with the Balkan Cluster for Health, Wellness and Spa tourism researchers to put together our hotly anticipated 2018 vision predictions (which will be announced again in April, during the World Health Sport Alternative Tourism Congress \& Exhibition: HESTOUREX-2019, which will be held between 4-7 of April 2019 in Antalya, Turkey.), I thought it fitting to take a step back and look at some of our previous predictions with a special emphasis on the Balkan vision we got right... and named before virtually anyone else.

\section{METHODOLOGY}

The research was done among 110 individuals (only 102 full responses): all Bulgarians, in 2017, ages 22 to 55 years old. There were 42 men and 60 women. The average age of the researched individuals was 34.5 years. For the purposes of the study the target group was divided into age groups (22 - 31 years; $32-41$ years; $42-55$ years), gender, work experience (less than 7 years, from 8 to 15 years and over 16 years), and rank (executives, managers and students in the field of Niche tourism). The research among the age groups was done in the biggest Bulgarians' resorts for Niche tourism (Varna, Bourgas, Pamporovo, Borovets), and the research among the students - during the last days of their summer semester (National sports academy, Sofia, they sign an agreement declaration). During the period of March-June 2017 a psychometric measurement of experts' opinions was conducted among Bulgarian professionals from various Wellness \& SPA \& Thalasso centres: employers, executives, investors, entrepreneurs, managers, executives and students from specific programs in the field. The experts' opinions were measured by an adapted version of the Survey Questionnaire for online use with Google Drive tools.

In order to fulfil the aim of the research we used: Psychometric assessment test. Grade psychometric measurement of experts' opinions is the result of the meanings of numbers (through the order for A-fixed question by-X of B-number of questions) placed on all questions asked (items). They reflect the quantity of the associated properties. We sort the questions according to the number of properties they possess. We obtain a range/grade scale for ranking the relative significance of the studied properties for the quality services and centres in the Bulgarian Niche tourism.

The aim of this study was to establish the quality assessment about standards for Wellness services and certified skills of specialized staff in the Bulgarian niche tourism by setting out a range scale by significance on the base of scientific indicators.

\section{RESULTS}

Table 1 summarizes the existing education and training programs worldwide by 2016 . This information is considered to be as accurate as possible, from the Global Wellness Institute (GWI - made by his research team) but the data are with the permissible standard error.

Perhaps there are other providers of special education who are not identified and were noted in the study - as is the Bulgarian case. Providers listed in the table are the conclusions in the Annual report of the GWI (cited and published with permission). They give evidences, according to the information compiled: online, by email, a site survey or filed by phone, that the Wellness Industry Global leaders are face of a serious lack of staff with specialised competences (11). 
DIMITROVA B.

Table 1. Types of educational or training programs for Wellness \& SPA worldwide

\begin{tabular}{|c|c|c|c|c|}
\hline \multicolumn{5}{|c|}{ Summary of Wellness \& SPA Management - Education \& Training programs on the sector } \\
\hline & \multirow[b]{2}{*}{$\begin{array}{|lrr|}\text { Total number } & \text { of } \\
\text { University/College } & \text { specific } \\
\text { programs } & / & \text { Vocational } \\
\text { education } & \& & \text { training } \\
\text { Centres } & & \end{array}$} & \multirow{2}{*}{$\begin{array}{l}\text { Total number } \\
\text { of Universities } \\
\text { / Colleges }\end{array}$} & \multicolumn{2}{|c|}{$\begin{array}{c}\text { Private companies } \\
\end{array}$} \\
\hline & & & $\begin{array}{|ll|}\text { Bachelor } & / \\
\text { Master } & / \\
\text { Doctoral } & \\
\text { Degree } & \\
\end{array}$ & $\begin{array}{l}\text { Short courses, } \\
\text { workshop, } \\
\text { seminars } \\
\text { Certifications }\end{array}$ \\
\hline Caribbean region & 3 & 1 & 1 & 7 \\
\hline Europe & 9 & 3 & 8 & 15 \\
\hline Latin America & 4 & 1 & - & 3 \\
\hline Middle East & 1 & 1 & - & - \\
\hline North America & 16 & 7 & - & 9 \\
\hline In the world & 41 & \begin{tabular}{|c|}
15 \\
\end{tabular} & 2 & 24 \\
\hline \multicolumn{5}{|c|}{ Balkan Region of Europe } \\
\hline Bulgaria & 7 & 3 & $6+1 \mathrm{PhD}$ & - \\
\hline Macedonia & 2 & - & - & 2 \\
\hline Turkey & 1 & - & - & 1 \\
\hline
\end{tabular}

Worldwide the training or educational instruments for the specific Wellness \& Spa management are missing or are few in number (12). Currently the optional modules are not connected with the specific activities or services of the costumers' needs. The elective modules are in the field of the economy knowledge, not with the required specific competences. Providers of continuing education are also new, fragmented and not "proven" model for effective delivery of training for employees already working in the Wellness sector (13). At present special problems in the management of Wellness business are of great concern: 1 .The challenges associated with current/future Wellness \& SPA managers and the requirements for a high level of skills acquired in their careers/path of growth; challenges in taking a management position, which requires interdisciplinary knowledge and competences harmonized with the tasks regarding the new Wellness Culture and people motivation for a healthy lifestyle. 2 . Specification or criterion about education in professional competencies of staff for Wellness is not well justified, so most governing staff (managers/directors/ managers/consultants/methodologists) have unilateral knowledge: only control or only therapies or only finance, or marketing, or motor practices aqueous environment. 3 . Analysing the views of experts of our survey in Bulgaria identified, we find six indicators for ranking the Wellness facilities and indicators for the customer expectations for the Wellness staff that they ranked by importance. Bulgaria is an absolute Balkan Educational Leader, with five accredited Wellness \& SPA \& Thalasso programs - from "bachelor degree" to "Doctoral" degree in two professional fields: Sport and Health Care. The results of our study (via psychometric experiment for registering the costumers and experts point of view) we have systemized and presented in Table 2 . The main criteria for assessing the quality and competitiveness of Wellness locations on the ground experts point of view (personal opinion) we produce a data ranking according to their significance (in grade units by their respective weights) and we obtained a ranking shows the importance and significance, which are.

The Wellness location (facility) indicators for high quality and preferences we define according to the significance via customers and experts regard and attitude. Their rankings by significance are the follow: The more important on first place is "The highly qualified and trained personnel". The selective efficiency must be according to specific criteria like a level of education or certification, the specialised skills and the practical experience. This indicator is with high significance (raking one, with $86 \%$ of experts regard with a personal point of view and 553 units). The next indicator is the "Standardisation of the quality services" according the EU standards about wellness \& spa locations/destinations" (Ranks two, with $65,5 \%$ of experts regard with a personal point of view and 473 units). Figure 1 is presenting the significance based on the scale of studied indicators during the quality assessment with customers and experts' point of view. 
Table 2. Range scale by significance based on the scientific indicators in the quality assessment for the Wellness locations (facilities).

\begin{tabular}{|c|c|c|c|c|c|c|c|c|}
\hline Indicators & $\begin{array}{l}1 \\
16 \\
\text { un. }\end{array}$ & $\begin{array}{l}2 \\
15 \\
\text { un. }\end{array}$ & $\begin{array}{l}3 \\
/ 4 \\
\text { un. }\end{array}$ & $\begin{array}{l}4 \\
/ 3 \\
\text { un. }\end{array}$ & $\begin{array}{l}5 \\
/ 2 \\
\text { un }\end{array}$ & $\begin{array}{l}6 \\
/ 1 \\
\text { un. }\end{array}$ & Sum & Rang \\
\hline $\begin{array}{l}\text { 1. The centre must employ } \\
\text { highly qualified and trained } \\
\text { personnel, selected according to } \\
\text { specific criteria like education, } \\
\text { skills and experience. }\end{array}$ & $\begin{array}{c}88 \\
86 \% \\
486\end{array}$ & $\begin{array}{c}12 \\
12 \% \\
60\end{array}$ & $\begin{array}{c}1 \\
1 \% \\
4\end{array}$ & $\begin{array}{c}1 \\
1 \% \\
3\end{array}$ & $\begin{array}{l}- \\
- \\
-\end{array}$ & $\begin{array}{l}- \\
- \\
-\end{array}$ & $\begin{array}{c}102 \\
\text { people } \\
553 \\
\text { Units } \\
\text { Rang } \\
\text { Weight }\end{array}$ & I \\
\hline $\begin{array}{l}\text { 2. The centre must meet } \\
\text { standards in the quality of } \\
\text { Wellness services and EU } \\
\text { standards regarding wellness \& } \\
\text { spa products. }\end{array}$ & $\begin{array}{c}9 \\
8,5 \\
\% \\
54\end{array}$ & $\begin{array}{c}66 \\
65,5 \% \\
330\end{array}$ & $\begin{array}{c}15 \\
14,5 \% \\
60\end{array}$ & $\begin{array}{c}6 \\
5,5 \% \\
18\end{array}$ & $\begin{array}{c}5 \\
5 \% \\
10\end{array}$ & $\begin{array}{c}1 \\
1 \% \\
1\end{array}$ & $\begin{array}{c}102 \\
100 \% \\
473\end{array}$ & II \\
\hline $\begin{array}{l}\text { 3. The centre must have state- } \\
\text { of-the-art facilities and } \\
\text { equipment }\end{array}$ & $\begin{array}{c}4 \\
3,5 \\
\% \\
24\end{array}$ & $\begin{array}{c}3 \\
2,5 \% \\
15\end{array}$ & $\begin{array}{l}70 \\
69 \% \\
280\end{array}$ & $\begin{array}{c}6 \\
5,5 \% \\
18\end{array}$ & $\begin{array}{l}10 \\
9 \% \\
20\end{array}$ & $\begin{array}{c}9 \\
8,5 \% \\
9\end{array}$ & $\begin{array}{c}102 \\
100 \% \\
366\end{array}$ & III \\
\hline $\begin{array}{l}\text { 4. The centre needs a detailed } \\
\text { investment project plan } \\
\text { concerning the areas of wellness } \\
\text { \& spa business development }\end{array}$ & $\begin{array}{c}1 \\
1 \% \\
6\end{array}$ & $\begin{array}{c}12 \\
12 \% \\
60\end{array}$ & $\begin{array}{c}6 \\
5,5 \% \\
24\end{array}$ & $\begin{array}{c}42 \\
41,5 \% \\
126\end{array}$ & $\begin{array}{c}4 \\
3,5 \% \\
8\end{array}$ & $\begin{array}{c}37 \\
36,5 \% \\
37\end{array}$ & $\begin{array}{c}102 \\
100 \% \\
261\end{array}$ & IV \\
\hline $\begin{array}{l}\text { 5. The centre must have } \\
\text { effective structure of governance } \\
\text { and procedures for management }\end{array}$ & - & $\begin{array}{c}4 \\
3,5 \% \\
20\end{array}$ & $\begin{array}{c}6 \\
5,5 \% \\
25\end{array}$ & $\begin{array}{l}20 \\
9 \% \\
20\end{array}$ & $\begin{array}{c}72 \\
71,5 \% \\
144\end{array}$ & - & $\begin{array}{c}102 \\
100 \% \\
209 \\
\end{array}$ & $\mathrm{~V}$ \\
\hline $\begin{array}{l}\text { 6. The centre must have } \\
\text { excellent image and } \\
\text { competitiveness. }\end{array}$ & - & $\begin{array}{c}5 \\
5 \% \\
25\end{array}$ & $\begin{array}{c}4 \\
3.5 \% \\
14\end{array}$ & $\begin{array}{c}27 \\
26,5 \% \\
81\end{array}$ & $\begin{array}{c}11 \\
10 \% \\
22\end{array}$ & $\begin{array}{c}55 \\
54,5 \% \\
55\end{array}$ & $\begin{array}{c}102 \\
100 \% \\
197\end{array}$ & VI \\
\hline
\end{tabular}

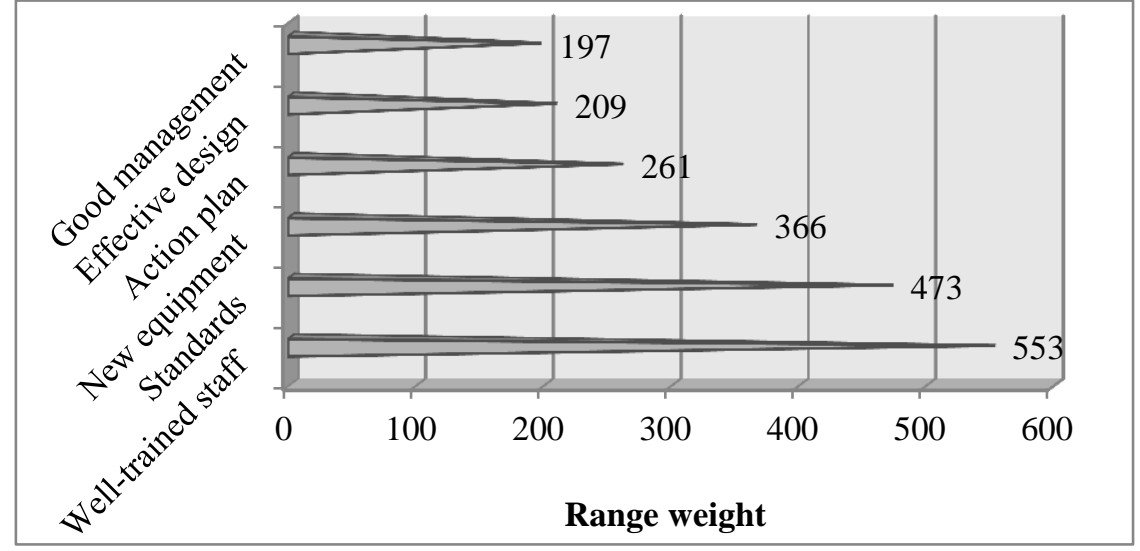

Figure 1. Importance range scale based on customers and experts point of view

Third and fourth are classified and ranked the indicators "State-of-the-art facilities and equipment" ( $3{ }^{\text {rd }}$ Ranking with $69 \%$ of experts regard with a personal point of view and 366 units) and "A detailed investment project plan" $\left(4^{\text {th }}\right.$ ranking. with $41,5 \%$ of experts regard with a personal point of view and 261 units) to be used concerning the areas of wellness \& spa location in order to develop a successful business Indicators: "An effective structure of governance and procedures for management" and "An excellent image and competitiveness" received $\left(5^{\text {th }}\right.$ ranking with $71,5 \%$ of experts regard with a personal point of view and 209 units; and $6^{\text {th }}$ ranking with $54,5 \%$ of experts regard with a personal point of view and 197 units). The scale order for the ranking of the rest of indicators (between 7 to 10 place), studied by the Balkan Cluster for Health, Wellness and Spa tourism, are as follows: a large spectrum of Wellness services; optimal pricing strategy; flexible marketing policy; favourable conditions of work and promotion of employees, but for this publication we make our preference only for six statements. From the data analysis, we find that the 1st and 2 nd positions are establish or originate on the professional qualifications or certification of 
the staff and the efficacy of the performance or execution of services. Figure 2 shows the links between metrics expressing the Influence and
DIMITROVA B.

directions existing between the well-trained staff and the service quality for acquiring high service quality-employee overall contribution.

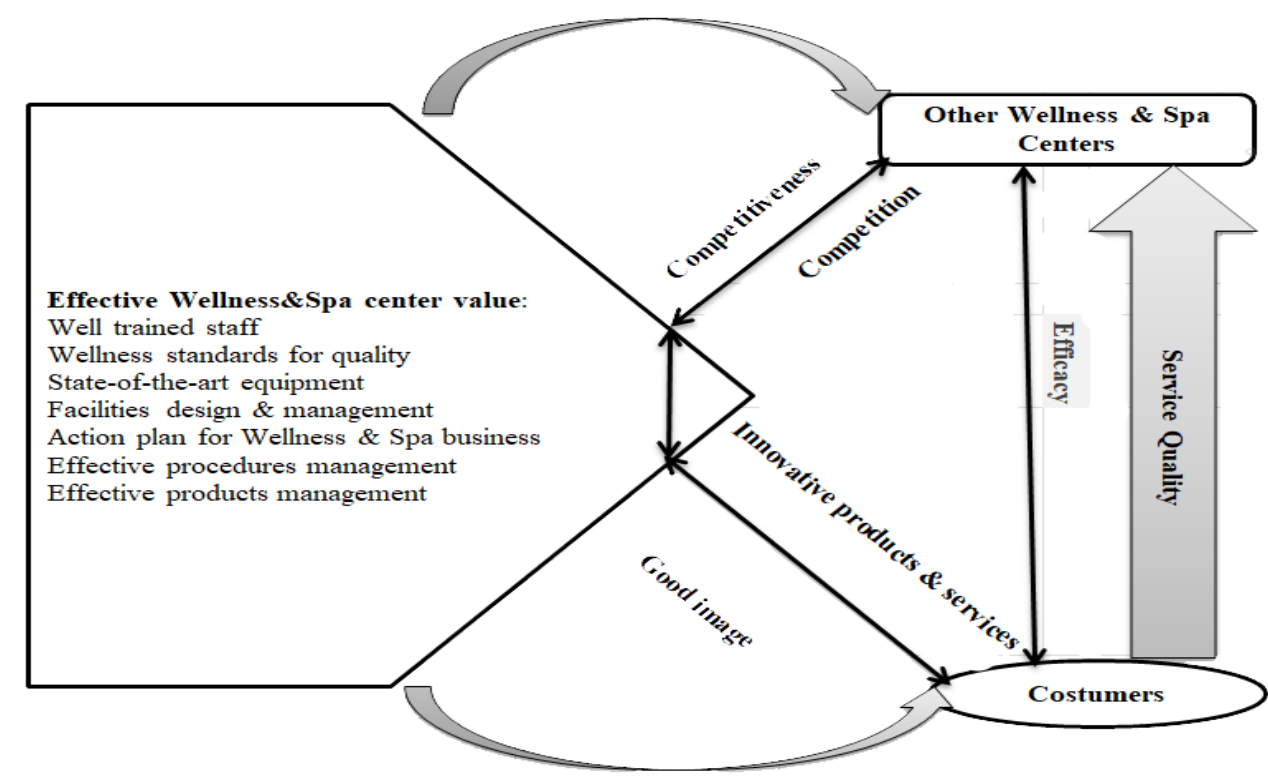

Figure 2. Influence and directions between the service quality-employee overall contribution

The experts' determination of the priority indicators in this survey, conducted to their ranking, should be considered when uniform standards will be introduced (in accordance with the European union criteria) by all public authorities responsible for the National categorization of Wellness \& Spa facilities and the National certification of staff in the wellness sector. A crucial need for training programs is established, during the survey. Future professionals in the wellness industry need a stable knowledge and competencies for effective organizational and methodical (Intellectual and practical knowledge and skills for different procedures and healthy influences, based on the natural resources), with a high level of professional performance to offer quality services tailored to the consumers need of wellness products and responding to their interests. In our study we found the necessity to activate the professional contacts between academic bodies, VET course providers, Secondary schools, professional educational bodies, for building a Bridge between the theory, the wellness business and the Industry sectors (with real practice in a real professional environment). In our position of scientific advisor of the Balkan Cluster for Health, Wellness and Spa tourism we supervise the modules structure and thematic orientation of the elaborated Syllabus, Standard and Curriculum (in the Erasmus +KA2, WELVET project: No 2016-1-BG01-KA202-023690). The Job profile contains 4 intellectual products in 5 languages and is with high added value to the EU educational and labour policies, which is expected to ensure inclusive smart growth.

\section{DISCUSSION}

The Wellness Instructor new job position is based on transnational cooperation effort of VET providers and economic actors in the field of wellness tourism created under the Erasmus+ KA2 WELVET project (2016-1BG01-KA202-023690, available now: https://wellnessproject.info/welvet-project-

2.html). The project's core intellectual output, Vocational education and training (VET) course for the emerging "wellness instructor" occupation, is addressing a pressing want for the European wellness tourism industry, namely the lack of trained staff to deliver highquality specialized customer service. It is important to create educational Wellness modules and levels of education in the teaching and training process in secondary schools and higher education (2).

The Wellness Instructor new job position equipping VET providers with new curricula to apply when delivering continuous VET to professionals already holding a vocational qualification in some of the occupations included in the professional field of Tourism 
and Hospitality. This would lead to filling in the gap for qualified staff to act as Wellness instructors in Niche tourism, due to this vocation still not being formalized in many countries at secondary education level. Our ambition is to also ensure that a continuous training process is delivered, adding additional units (learning outcomes) to already acquired qualifications and levels, thus contributing to increase employability and consistency with the tourist and hospitality sector's current needs. In addition, the Wellness Instructor new job position will propose a unique delivery method by designing, testing and producing a Smart mobile Application, in order to ensure free and open access to innovative training embedded in the digital era.

The Wellness Instructor new job position further resonates the main new features and meta priority lines of Erasmus+ such as dissemination and exploitation of results (the project consortium covers 4 main regions of Europe - South-Eastern (Bulgaria and Macedonia), Central (Austria) North (Estonia) and Western Europe (United Kingdom), open access to education products (the WELVET Wellness vocational education and training learning application was developed and is available for free at Google play store under the title: "Wellness Instructor-New Job position") and multilingualism (the project delivers products in 5 languages (English, Bulgarian, Estonian, Macedonian and German).

Bulgaria is a country opening up to alternative forms of Niche tourism to attract more clients from the global market. Wellness tourism is seen also as a source for ensuring sustainable development of rural regions and other regions wanting to develop four seasons (e.g., the area of Rila Mountain) touristic attractions. Bulgaria has developed a high percentage of the hotel infrastructure to incorporate elements of the wellness tourism, such as healthy food, opportunities for outdoor Wellness activities, and links to natural resources (such as mineral springs). The key challenge is to ensure that clients are aware of the diverse wellness opportunities offered and receive the appropriate guidance and follow-up by the respective staff. Bulgaria can become a leading global provider of wellness products. Nevertheless, the question of maintaining quality is, even more, pressing in the light of rising global competitors such as Asia-Pacific countries. In Bulgaria, there is a strategic goal of promoting countryside as tourist destinations. Currently around almost twothirds of critical vacancies in the sector are due to skill shortages, the majority of which are for elementary staff and skilled trade occupations.

\section{CONCLUSIONS}

In conclusion, on the basis of the survey, we believe that joint action is needed, in collaboration with the professional associations and non-governmental organisations for the development and adoption of state regulatory tools in the Bulgarian Niche tourism:

1. Setting standards for categorization of Wellness \& SPAs and quality assessment procedures and services;

2. A want for introducing the requirements for qualification of personnel in the Niche tourism and Bulgaria have the potential to become a European educational leader (with 7 specific programs);

3. Increasing competitiveness of SPAs at National and Balkan level expanding horizons of services, products, packages and programs, having arguments for balanced prices, promotions and strategic vision for sustainability covered by investment funds;

4. Providing specialized training of personnel with secondary and higher education (in National sports academy on "Bachelor" or "Master" degree and the "Doctoral degree - Philosophy Doctor$\mathrm{PhD"}$ );

5. Developing regulations with a harmonized system on the European level with strong requirements for the applied programs and procedures in the SPA \& Wellness \& Thalasso locations and a Bulgarian strategy for the development of the Niche tourism.

6. Implementing these priorities, along with extremely advantageously natural factors will contribute to making Bulgaria a preferred Niche tourism destination.

\section{REFERENCES}

1. Ignatov, I., Water in the Human Body is Information Bearer about Longevity. Paper presented at the World Scientific Conference "Chemistry, Physics and Biology of Water", Proceedings, Vermont Photonics, NY, pp 57-58, 2012.

2. Trendafilov, D., Dimitrova, B., Aqua Spinning as anti-stress health prevention. Sport Mont, XI (37-38-39): 467-473, 2013. [Internet],http://www.sportmont.ucg.ac.me/ ?sekcija $=$ article $\&$ artid $=73$ 
3. Polimenov, M., Inovation in SPA and enology as opportunity to raise the Competitiveness of tourist services. Paper presented at the Intrenational tourist forum Spa and wine. South-West University "Neophyte Rilski". Proceedings, Blagoevgrad, Bulgaria, pp 163, 2014.

4. Wang, W., Hou, Y., Hu, N., Zhang, D., Tao, J., Man, Y., A cross-sectional study on health-related knowledge and its predictors among Chinese vocational college students. BMJ Open, 4(10), e005182, 2014.

5. Nesheva, I., Benefits of the physical activity and the elaborated program mental prevention gym for women with normal pregnancy. Research in Kinesiology, 43(2): 210-214, 2015.

6. Commission of the European Communities, Together for Health: A Strategic Approach for the EU 2008-2013, EC, 2007.

7. Doncheva, L. \& Dimitrova, L., Innovative Way of Teaching English in Class and Its Influence on Pupils' Level of Concentration. Paper presented at the Vth Congreso de Internacional de Competencias Básicas, 13-15 de Abril 2016: la competencia en comunicación lingüística, Ciudad Real, pp 21, 2016.
DIMITROVA B.

8. Global Wellness Institute, Economy Report. GWI, Miami, USA, 2014. [Internet],http://www.globalwellnesssummi t.com/images/stories/gwi/GWI_2014_Glob al_Wellness_Tourism_Economy_Report_Fi nal.pdf

9. Dimitrova, B., New smart educational model - Wellness instructor. Avangrd Prima, Sofia, Bulgaria, 2019.

10.Pesheva, P. , Velkova, A., Georgieva , L., Georgieva, E., Hristov, N., Pravchanska, M., Functional health literacy of students of the Medical university -Sofia. Trakia Journal of Sciences, Vol. 16, Suppl. 1: 5559, 2018. [Internet], http://tru.unisz.bg/tsj/Vol.16,\%20Suppl. 1,\%202018/11.pdf

11.Global Wellness Institute, Global wellness tourism economy. Wellness Industry Research, GWI, Miami, USA, 2018. [Internet], https://globalwellnessinstitute.org/industryresearch/global-wellness-tourism-economy/

12.Egan, S., Fitness \& Health, A holistic approach. Grimcare. Ottawa, Canada,1984.

13.Valev, Yu., Kontrol i otsenka na sportnata podgotovka $\mathrm{v}$ konniya sport, , NSA „V. Levski“, Sofia, Bulgaria, 2015. 